\title{
El fenómeno de la "edicionalización" y la prensa local
}

\author{
Dra. Antonia González Borjas \\ Responsable de Comunicación en el \\ Hospital Universitario de Valme (Sevilla)
}

\begin{abstract}
El auge experimentado por la Prensa local en los últimos años tiene como correlato el interés empresarial de los Mass-Media por satisfacer demandas limitadas a zonas determinadas. Como consecuencia de ello, el periódico local se ha visto acompañado del fenómeno de la "edicionalización", proceso mediante el cual los Medios de difusión nacional o regional han logrado un nuevo producto informativo para ciudades distintas con tan sólo cambiar parte de su logrado un nuevo producto informativo para ciudades distintas con tan sólo cambiar parte de su
paginación. Esta dialéctica lleva consigo un doble comportamiento mediático: el rol de contenpaginación. Esta dialéctica lleva consigo un doble comportamiento mediático: el rol de conten-
ción por parte de las publicaciones locales, mientras que la Prensa de ámbito mayor desarrolla el expansionismo informativo.
\end{abstract}

\section{Introducción}

C a irrupción de las nuevas tecnologías informativas en el periodismo escrito ha facilitado la viabilidad técnica del pequeño periódico (o diario local), puesto que los procedimientos innovados permiten realizar publicaciones con poco equipamiento y reducir a un mínimo el personal técnico necesario. Pero, además, este hecho viene acompañado de las iniciativas de las grandes publicaciones que utilizan los citados avances para alcanzar a un potencial informativo casi ignorado: el correspondiente a la Prensa cercana (léase regional, provincial, comarcal o local). En efecto, «fruto del protagonismo adquirido por esta modalidad de información, emerge el fenómeno de la edicionalización en la prensa española» ${ }^{1}$.

En este nuevo modo de trabajar de los grandes, el fenómeno de la «edicionalización» se ha convertido en uno de sus recursos estrella. Así, la tecnología está permitiendo un acercamiento de los grandes Medios impresos a los más apartados lectores, incluyendo en las ediciones regionales los contenidos propios de cada zona geográfica. Luego las nuevas tecnologías de la información favorecen tanto a la Prensa local como a las páginas locales que los Medios gene-

CÁRDENAS RICA, M. Luisa y GONZÁLEZ BORJAS, Antonia: «Información local: democratización e interacción comunicacional», en AA.VV.: Comunicar: aprender a vivir. Actas del XXIX Congreso Universitario Internacional UNIV' 96, Ed. Kronos, Sevilla, 1996, p. 77. 
ralistas rehacen con ediciones zonales distintas, «por cuanto están permitiendo un mayor y más rápido acercamiento a las informaciones, no sólo de los profesionales de la información, sino también de las audiencias de los medios de comunicación» $»^{2}$.

Como resultado del elevado coste de la renovación tecnológica y del acelerado proceso de concentración de Medios, los beneficiarios han sido claramente los grandes y pequeños, mientras los Medios medianos han entrado en una situación de somnolencia. Es decir, se está produciendo el fortalecimiento de las grandes empresas, pues son las que realmente pueden acometer la renovación tecnológica, consolidándose los diarios de tiradas altas. Por otro lado, estamos asistiendo al renacimiento de los pequeños periódicos que, centrados en la información de lo cercano e inmediato, aumentan tanto en número como en cifras totales de tirada y vuelven a los orígenes del periodismo impreso, la información local. En el centro quedan los Medios de difusión media, los cuales sufren el estancamiento ante la imposibilidad de regenerarse tecnológicamente y la competencia de los Medios locales ${ }^{3}$.

La consecuencia de todo esto es una dialéctica entre las publicaciones locales -que asumen un rol de contención-, y las grandes empresas nacionales -que desempeñan un papel basado en la expansión-. Una tensión que reitera la producida entre grupos multinacionales y la Prensa nacional, señalado por los expertos como el gran marco del juego informativo mundial:

«Una tendencia de expansión central, cuyo eje se asienta en los grandes grupos de irradiación que encuentran en la combinación preimpresión integrada/ telecomunicaciones la base tecnológica de un libre flujo centrífugo -centro-periferia- proyectado sobre plantas satélites de impresión. Tendencia reproducida, a escala nacional, por los periódicos centrales, que, en base a la tecnología de irradiación, diversifican la oferta de ediciones descentralizadas, en competencia directa con los medios periféricos regionales o locales $\rangle^{4}$.

\section{El periódico local}

Con la conversión de nuestro país en un Estado de Autonomías, se han producido transferencias en distintos ámbitos. La información es uno de ellos $\mathrm{y}$, como resultado, se ha enriquecido su dinámica regional. 2 Acerca de la influencia del progreso tecnológico en la diversificación geográfica del periódico, véase CANGA LAREQUI, Jesús: «Del tipo móvil a la redacción electrónica. Apuntes sobre la evolución tecnológica de las labores redaccionales en el medio Prensa», en BEZUNARTEA, Ofa y otros: La prensa ante el cambio de siglo, Ed. Deusto, Bilbao, 1988, pp. 47-86; y COCA GARCIA, César: «La redacción electrónica: su impacto en el trabajo del periodista y en la diversificación del periódico», en BEZUNARTEA, Ofa y otros: op. cit.,
pp. 87-122. pp. $87-122$.

Vid. BENITO, Ángel: La invención de la actualidad. Técnicas, usos y abusos de la información, Fondo de

Cultura Económica, Madrid, 1995 , pp. $207-216$.
LALLANA, Fernando: «El color y la forma, piezas decisivas en la revolución de los periódicos», Boletín de Fundesco, $\mathrm{n}^{\circ} 85$, septiembre 1988, pp. 17 
La demanda social de información local se ha acentuado en los últimos años como consecuencia de la fragmentación de la audiencia en función de sus intereses dentro de la sociedad de la multi-información. Se trata de un proceso paralelo al vivido por el individuo desde el punto de vista existencial. Es decir, lo que filosóficamente se ha denominado búsqueda de la identidad personal del individuo moderno, tiene su analogía en el ámbito comunicacional. Y es en el seno de la sociedad actual donde la audiencia protagoniza la demanda de Medios locales como individualizadores de la información ${ }^{5}$.

La respuesta a esa demanda informativa localizada se debe realizar desde la Prensa escrita con contenidos que la satisfagan y con planteamientos tecnológicos y empresariales que aseguren la estabilidad del periódico local. No es de recibo que los periódicos locales copien a los nacionales en el apartado de contenidos, pues la diferencia de recursos entre los dos Medios y las expectativas de los lectores hacia ambos son abismales, por lo que la competencia es absurda. En la cuestión empresarial, por su parte, hay que limar los triunfalismos de aficionados al Periodismo. En este sentido, Antonio Checa advierte sobre

«la necesidad de no improvisar, de rehuir optimismos fáciles y de dotar a la nueva empresa periodística de un respaldo financiero importante (...), pero la experiencia enseña que el amateurismo es en exceso frecuente en los nuevos proyectos periodísticos y que puede lastrar desde un principio al nuevo diario que nace $»^{6}$.

A pesar de la importancia de este fenómeno informativo, calificable de «localismo», su relevancia no ha comenzado a ser reconocida en nuestro país hasta estos momentos. Todo lo próximo, lo cercano, lo local, se ha ignorado e identificado durante mucho tiempo con el folclorismo. No obstante, la información local no es de reciente aparición: «En sentido estricto, prácticamente todos los grandes diarios tuvieron un nacimiento 'local'. Tal es el caso del primer diario de la Europa continental, el 'Diario de Barcelona' (1792). Y también en Madrid nos encontramos con lejanos precedentes nada menos que de la Prensa local, en la provincia, y de la Prensa de barrio, en la capital: 'Crónica de los Carabancheles' (1897), 'La Región de Getafe' (1914), 'El Heraldo de Chamberí' (1921) o 'La Voz del Distrito de Universidad' (1931)»’

5 GONZÁLEZ BORJAS, Antonia: Producción de Medios locales: el caso de Estepa (Sevilla). Periódicos, re

vistas y emisoras entre 1882 y 1995, Tesis doctoral sin publicar, FCCI, Sevilla, 1998. 1983, pp. 46.

7 MACIÁ MERCADÉ, Juan: «La fuerza del periodismo local en la era de la globalización electrónica», en Estudios de Periodística V. Número especial dedicado al Periodismo Local, Sociedad Española de Periodística, 1997, p. 55 
Por su parte, la Prensa local (o último escalón en la estructura informativa) se ha convertido en los últimos años en el punto de mira de los grandes grupos de Prensa, de ahí que la primera se haya topado con las estrategias ofensivas de los segundos. Entre las fórmulas de penetración que han ensayado los grupos de Prensa contra los pequeños periódicos destacan tres ${ }^{8}$ :

- Edición de la misma cabecera en distintas zonas geográficas del país, incluso algunas de ellas con impresión en el lugar de difusión (como ejemplos: $E l$ País Cataluña o $A B C$ de Sevilla).

- Localización de la cabecera en distintos puntos de la geografía española, con la creación de sociedades cuyo capital es compartido con personas físicas o jurídicas enraizadas en el lugar de edición (Grupo 16, El Mundo).

- Compra de diarios, mayoritariamente líderes de zona, y posterior integración de los mismos en el grupo matriz. En este sentido, destacan El Correo, Prensa Ibérica y Zeta.

La tercera fórmula se ha perfilado como la más fructífera desde el punto de vista de la difusión informativa y de la evolución publicitaria. Se trata del resultado de la tendencia hacia la concentración experimentada por la Prensa escrita. Dicho proceso está perfectamente sintetizado en la «teoría de la sombrilla»de Rosse ${ }^{9}$. Según este teórico, centrado en el modelo norteamericano, los diferentes ámbitos geográficos se solapan. Esta superposición provoca un desequilibrio entre las opciones, puesto que las sombrillas mayores (que representan a periódicos expansivos) ciegan la información de las menores (que serían los Medios regionales y locales). Y, en esta aproximación a la información cercana, entran en juego las distintas fórmulas indicadas con anterioridad.

Frente a las estrategias de pugna por la audiencia seguidas por los grupos de Prensa, los pequeños periódicos locales y provinciales también han apoyado su respuesta en las nuevas tecnologías. Al verse casi maniatadas, las publicaciones locales independientes encuentran como única salida la concentración o concertación de servicios comunes. Esta actuación defensiva permite simultáneamente la elaboración de una estrategia encaminada hacia la captación publicitaria de amplio ámbito, como resultado de los espacios de difusión de los Medios coaligados ${ }^{10}$.

8 Vid. BEL MALLEN, José Ignacio: «La prensa regional y local: un proceso continuado de expansión», en Comunicación Social 1994/Tendencias, Informe anual de Fundesco, Madrid, 1994, pp. 209-222. COMPAIGNE, Benjamin: The newspaper industry in the 1980s. An assesment of economic and technology, White Plains, Nueva York, 1980, p. 102

10 DÍAZ NOSTY, Bernardo; LALLANA, Fernando y TIMOTEO ÁLVAREZ, Jesús: La nueva identidad de la Prensa, Fundesco, Madrid, 1988, pp. 96 y 97. 
3. La «Edicionalización»

El periódico expansivo, generalmente de ámbito nacional, se ha visto obligado a recurrir a una fórmula ofensiva encaminada a amainar el auge de la Prensa regional, provincial y local. Como filosofía que inspira esa deseada multilocalidad, éste ha apostado con gran fuerza por la «edicionalización».

Nos referimos a un proceso mediante el cual existe la posibilidad de cambiar un gran número de páginas de un mismo diario, sin detener su proceso de impresión, para lograr una infinita combinación de ediciones zonales. Para conseguir esto, el tratamiento redaccional corre a cargo de periodistas, situados en la zona geográfica determinada; mientras la vertiente técnica está basada en: preimpresión centralizada, vías de transmisión facsimilar e impresión multilocacional Por lo que respecta a la toma de decisiones, ésta se descentraliza en las ediciones locales, aunque la sede central siempre está informada de lo que se publicará.

Por lo que respecta a los procedimientos para llevar a cabo la «edicionalización», podríamos citar los siguientes: primar las noticias del área sobre las que ejerce influencia, valorar el localismo y lo cotidiano, interés por las cuestiones que llaman la atención del lector y mueven su curiosidad, ofrecer una tribuna al lector para exponer sus preocupaciones más cercanas, realizar ediciones o periódicos integrados en grandes cadenas con una cobertura común y suficiente de información general, utilizar una tecnología sofisticada que permita la multiplicación del mensaje y rapidez en la aparición, entre otros ${ }^{11}$.

El primer gran ejemplo del periodismo multilocacional viene representado por el diario USA Today. Desde un gran centro periodístico se envían a casi treinta sedes diferentes las páginas centrales del diario que contiene la información sobre política internacional, sociedad, economía y deportes. En cada ciudad se añaden las páginas de local correspondientes y se imprimen en pequeñas imprentas. A través de la zonificación del Medio los distintos receptores adquieren un cuerpo común de información, nutrido de recursos normalmente inalcanzables para la Prensa periférica independiente. De esta forma, el gran periódico se aproxima a los lectores en dos apartados: en contenidos, compitiendo con las publicaciones regionales, provinciales y locales, y en rapidez de distribución de los periódicos de las distintas zonas mediante la impresión simultánea en plantas periféricas. El producto final «es un medio con contenidos informativos y publicitarios locales, aunque inserto en una estructura superior $\mathrm{y}$, por consiguiente, dentro de una oferta más global y completa» ${ }^{12}$. Si bien, después de reconocer el esfuerzo que hacen ciertos diarios por acercarse al máximo a la localidad, también hay que ratificar que no por ello éstos pierden sus características de periódico de masas: se rigen por el

11 Vid. PEÑALVA ABRISQUETA, José Luis: Prensa regional y nuevas vías de acercamiento al lector, Tesis doctoral inédita, Universidad del País Vasco, 1987.

12 DÍAZ NOSTY, Bernardo; LALLANA, Fernando y TIMOTEO ÁLVAREZ, Jesús: op. cit., p. 89. 
modelo imperante en la recepción de la noticia, la tirada, los contenidos, la tecnología y el tratamiento general de la información.

En esta lucha de los Medios por ofrecer informaciones más localizadas, podemos preguntarnos que quiénes fueron los pioneros en el fenómeno de la edicionalización. Para su respuesta basta detenernos en la competitividad por la cobertura. En efecto, si la competencia natural de los diarios nacionales son los regionales y la de los regionales los provinciales, comarcales y locales, fueron los grandes periódicos regionales sus verdaderos impulsores ${ }^{13}$. Actualmente, la $\mathrm{Co}-$ munidad con mayor número de ediciones zonales es Galicia. Una expansión periodística fundamentada en la potenciación de la información local a través de un total de treinta ediciones territoriales. En el País Vasco se registran otras veinticinco y en la Comunidad valenciana dieciocho ${ }^{14}$. Sin duda, los grupos de Prensa de regiones, con una dinámica empresarial muy parecida a la de los grupos centrales, han intensificado su expansión a través de la diversificación zonal.

Lógicamente, a la estrategia de territorialización de ediciones en pro de una mayor eficacia en la penetración regional se apuntaron de inmediato los diarios de ámbito nacional. Un caso muy representativo lo constituye Diario 16 que, además de su edición nacional, contaba en 1995 con ediciones en Andalucía, Aragón, Baleares, Burgos, Galicia, Málaga, Murcia y Valencia. Pero abordamos una aureola localista que no empaña la parquedad vertida hasta el momento por los diarios de tirada nacional españoles. El Mundo, uno de los pocos periódicos que medita acerca de este fenómeno, reconoce ese desarraigo hacia lo local vivido en nuestra Prensa: «A menudo 'municipal y espesa', la información local no ha sido nunca en los periódicos españoles de difusión nacional una columna vertebral como lo es en otros países» ${ }^{15}$. Del mismo modo, este Medio justifica con tintes puramente sociales su adhesión al carro de la «edicionalización»; si bien, está dentro de toda lógica su incursión a lo zonal por motivos fundamentalmente empresariales: «Sin pretender invadir el terreno de los diarios de ámbito más reducido, regionales o provinciales, EL MUNDO pretende sacar esa información del gueto de la marginalidad $»^{16}$. Sus responsables optan también por imprimir notoriedad a esta sección o área informativa, extrayéndola de cualquier discriminación, por todo lo cual consignan los mismos principios de legibilidad, precisión, combinación de datos y testimonios humanos y de búsqueda más allá de lo que digan las versiones y notas oficiales que se apliquen en el conjunto de las demás secciones. Este diario coloca como núcleo central de la información local a la vida pública de los

13 Vid. MACIÁ MERCADÉ, Juan: La comunicología regional, dinamizadora de la estructura comunicacional española, Tesis doctoral, Ed. Universidad Complutense, Madrid, 1992, p. 280.

15 "Áreas informativas», en AA.VV.: Libro de Estilo de EL MUNDO, Ed. Temas de Hoy, Madrid, 1996, p. 38 16 Ibídem. 
municipios grandes y pequeños que tan directamente afecta a los lectores. Para ello, destaca tres planos primordiales: el político (actividades de los cargos públicos y de los candidatos en períodos electorales, los plenos municipales), el económico-presupuestario (gastos, inversiones y tasas públicas) y el urbanístico (planificación, cambios de uso, obras públicas). Sin embargo, lejos de lo que los ajenos a la información local puedan pensar, las ciudades o municipios no sólo producen información en torno a su Casa Consistorial. La información local moderna debe considerarse como un abanico de intereses cada vez más amplio: problemas sociales, servicios, estilos de vida, fiestas, crítica urbanística..., en definitiva, subsecciones que conforman en sí mismas un todo informativo, lo local, representante de una especialidad informativa.

Por otro lado, la proliferación de ediciones zonales no sólo ha afectado a los periódicos nacionales y regionales; sino que también ha calado en periódicos locales con vocación regional. En Andalucía son representativos los casos de Ideal (que realiza ediciones especiales para Jaén y Almería), Sur (con ediciones para la Costa del Sol y Melilla) o $A B C$ de Sevilla (que pone en práctica las ediciones zonales en Jerez, Córdoba y Huelva) ${ }^{17}$. Más aún, la cobertura del entorno inmediato ha desbordado a la Prensa de información general para también hacer acto de presencia en la Prensa especializada. Sin ir más lejos, el diario deportivo más leído en España, Marca, dispone de distintas ediciones.

Esta descentralización informativa también lleva pareja la descentralización comercial, la cual se acentuará precisamente en 1995. Según Díaz Nosty asistimos a una transformación de pequeñas ediciones zonales en versiones mucho más diversificadas o en cabeceras más netamente diferenciadas:

«Así, El País introdujo sustanciales mejoras en su versión catalana, la más veterana del diario madrileño; también Unidad Editorial proyectó sobre el espacio informativo catalán la cabecera El Mundo de Catalunya, aparecida el 20 de septiembre, impresa en Castellbisbal, en competencia con otra edición de la prensa cultural, la de ABC, producida en los talleres del diario Sport, del grupo Zeta (...)El País comenzó en 1995 la producción descentralizada, en plantas de impresión propias, situadas en Valencia y Dos Hermanas (Sevilla) de las ediciones personalizadas de la Comunidad Valenciana y Andalucía, además de una edición satélite para Galicia, realizada en los talleres del Faro de Vigo, posteriormente en Prensa Ibérica. Unidad Editorial inició en abril una versión específica para la Comunidad gallega, El Mundo de Galicia, sobre el mismo territorio donde compite también Diario 16 de Galicia, cuya empresa editora pasó a ser controlada en un 70 por ciento por Inpresa, propietaria del periódico matriz de la cadena 16. El

17 GUERRERO SERÓN, Carlos: Los andaluces y los medios de comunicación, Ed. Junta de Andalucía, Consejería de la Presidencia, Sevilla, 1995, p. 81. 
periódico del grupo Prisa, El País, anunció también un nuevo punto de su producción multilocacional en Burgos, destinado a centralizar la distribución del Norte del país, tras un acuerdo con Diario de Burgos, en cuyos talleres se imprime asimismo otra edición de Marca. Unidad Editorial, a través de medios impresos filiales, imprime en Benavente (Zamora) la versión territorial El Mundo de Castilla y León, desgajada de El Mundo de Valladolid, aparecida en 1994» ${ }^{18}$.

Para corresponder a esa audiencia más delimitada hay que tener muy presente el orden de prioridades de contenidos de la misma, de ahí que sea necesario un estudio del índice de lectores y su capacidad adquisitiva, la segmentación de la audiencia, etc. O sea, llevar a cabo una auténtica sociología periodística. Y es que, como dice F.R. Hutin, director general del más importante diario regional francés con sus 35 ediciones diarias, Ouest-France, «a los franceses les interesa más su dolor de muelas que la muerte de un millón de chinos $»^{19}$. Un Concepto que es perfectamente trasladable a cualquier país, donde el ciudadano se interesa en primer lugar por la actualidad de su entorno más inmediato, después vendría la curiosidad por el resto del país y del mundo en el que vive. Efectivamente, el periódico regional, provincial y local debe dar respuesta a múltiples expectativas:

«No sólo ha de servirse una información nacional e internacional que enmarque la actualidad regional en un mundo cada vez más concatenado, sino que la dinámica informativa ha de potenciar al máximo en el enraizamiento de los individuos en sus comunidades. Se trata de reflejar la vida de las instituciones locales, en generar conductas colectivas, capacidades de discernimiento(...) $\rangle^{20}$.

Pero en ese trozo del rotativo de contenido informativo localizado también tiene cabida la publicidad adaptada a cada zona. Junto a la conquista de audiencia, la publicidad se perfila como el otro gran pilar reforzador del negocio de la «edicionalización», ya que cada edición acaparará publicidades distintas y con ello ingresos múltiples. En este sentido, José Luis Peñalva, que preparó la edicionalización de El Correo Español-El Pueblo Vasco, subraya que «la decisión de comarcalización tiene como referencia, en unos casos, la territorialidad; en otros, la diversidad étnica o cultural y siempre el intentar una respuesta comercial extendiéndose en unos espacios de comunicación diferentes a los ya ocupados. Algunas empresas españolas al intentar adaptarse a la información local, ensayan

18 DÍAZ NOSTY, Bernardo: «Informe sobre los medios en España», en Comunicación Social 1995/Tendencias,

Informe anual de Fundesco, Madrid, 1995 , pp. 69 y 70 .
19 YBARRA, Enrique: «'Edicionalización’ para mejorar la cobertura regional», en $A E D E, \mathrm{n}^{\circ}$ 7, marzo 1983, 9 YBAR
p. 9. p. 9.
20 Ibídem, pp. 11 y 12 . 
un modelo mixto inspirado en el americano que se agrupa por cadenas y el francés que se multiplica en ediciones. Ambas propuestas exigen factores de producción suficientes y tecnología avanzada. Todo ello sostenido por el soporte financiero publicitario fácil de dominar a través de las páginas locales $»^{21}$.

Como conclusión, lo más sobresaliente de esta competitividad entre pequeños/grandes, desprotegidos/consolidados, periféricos/centrales, es el beneficio informativo de los lectores locales ${ }^{22}$. O sea, como contraprestación al interés desarrollado por los Medios de Comunicación expansivos hacia lo regional, la misma Prensa regional se ha visto obligada a descender al reducto más localizado de la información (las ediciones locales) con el propósito de ser la primera en su especialidad. En el seno de este proceso, los públicos sienten correspondidas sus necesidades informativas más inmediatas. Precisamente por ello, el sistema de ediciones parece constituir una fórmula de éxito para la empresa de Prensa del año 2000, en la cual la información general tendrá que compaginarse necesariamente con la información más cercana a los lectores ${ }^{23}$.

\subsection{Defensores y detractores}

En realidad, parece contradictorio cimentar el protagonismo de la Prensa local en la incapacidad del periodismo para tratar temas cercanos cuando, precisamente, abordamos el éxito de los diarios de gran difusión a partir del tratamiento de la información local. No obstante, la filosofía de la multilocalidad que inspira la «edicionalización» hace que nos encontremos con dos tipos distintos de información local: la que ofrecen los diarios de información general y la que ofrece la Prensa local. María José Cantalapiedra reconoce esta realidad del siguiente modo: «Los medios de comunicación locales, y concretamente las publicaciones locales, pueden y deben ofrecer aquello que no ofrecen los periódicos regionales en sus ediciones locales. Esa es al menos su carta de presentación. Así tenemos que hay dos tipos de información local»» ${ }^{24}$.

A este respecto, hay autores que defienden la producción de ediciones distintas de diarios para mejorar la cobertura territorial y otros que la consideran insuficiente. En el apartado de los detractores se encuentra Picos Freire, quien reprocha a la Prensa de información general que «los diarios no logran darle al

21 Citado por CAL MARTÍNEZ, Mª Rosa: «Fórmulas nuevas de información local», en TIMOTEO ÁLVAREZ, Jesús y otros: Historia de los Medios de Comunicación en España. Periodismo, imagen y publicidad (19001990), Ariel Comunicación, Barcelona, 1989, p. 496.

22 GONZÁLEZ BORJAS, Antonia: op. cit

23 GARCÍA GONZÁLEZ, Aurora: «Prensa local y periodismo del 2000. El caso de La Voz de Galicia», en Estudios de Periodistica V. Número especial dedicado al Periodismo Local, Sociedad Española de Periodís-
Estudios de Periodística
tica, 1997, p. 175.

24 CANTALAPIEDRA, María José: La información local en los periódicos de Bizcaia, Tesis doctoral, Servicio Editorial de la Universidad del País Vasco, Bilbao, 1996, p. 23. 
lector la sensación de identificación que éste experimenta al leer un periódico dedicado únicamente a las noticias de su propia colectividad $\aleph^{25}$.

Enrique Ybarra, por su parte, destaca varias virtudes de los huecos locales que dejan los grandes periódicos: «Las páginas locales colaboran en la fiscalización de la acción política en planos más bajos; dan seguridad, inconscientemente, al reflejar las conductas cambiantes de un medio dinámico, difícil e incluso hostil, como puede llegar a ser la sociedad de hoy. La edición funciona así como un espejo de la vida social de esas colectividades que desean contemplarse y encontrarse en el reflejo periodístico. (...)Pero además, del papel de seguridad, el diario regional con incidencia local tiene otro: la ayuda a la evolución $»^{26}$.

Otro investigador de la información local, Maciá Mercadé, cuestiona el éxito final del esfuerzo realizado por los Medios provinciales, regionales o nacionales para cubrir con mayor amplitud y profundidad la información de comarcas y localidades. En realidad, es obvia la inexpugnabilidad del trabajo realizado «in situ» del periodismo local con respecto al realizado mediante delegaciones locales o corresponsalías. En este sentido, Maciá Mercadé califica de insuficientes las corresponsalías y llega además más lejos, pues demuestra cómo la información que aparece en los rotativos regionales o nacionales de una determinada zona es insuficiente, distorsionada y manipulada ${ }^{27}$. Frente a esto, la Prensa local utiliza el argumento de la validez de una edición única, tachando de «localismo manipulado» el realizado por los Medios regionales y, por extensión, los nacionales. No obstante, debemos tener presente que el periodismo local es complementario al general y en ellos no cabe la competencia; sino que, por el contrario, nos referimos a dos niveles distintos y específicos. Ambos responden a demandas informativas diferentes. Acerca de esta complementariedad, el citado autor también hace referencia a los equipos empresariales y periodísticos de la Prensa comarcal, los cuales

«Tienen el convencimiento de estar respondiendo a una demanda informativa difícilmente asumible por la prensa diaria de mayor alcance, que ya realizó experiencias en este sentido (suplementos comarcales específicos según áreas de

25 PICOS FREIRE, José Juan: «Estructura de la información local en España», en EL-MIR, Amado José y VALBUENA DE LA FUENTE, Felicísimo (compiladores): Manual de periodismo, Prensa Ibérica/Univ. de Las Palmas de Gran Canaria, Barcelona, 1995, p. 608.

26 YBARRA, Enrique: op. cit., p. 12.

27 MACIÁ MERCADÉ, Juan: «La fuerza creciente de la noticia local», en Anuncios, 2-8 febrero 1987, p. 4. El autor se basa en un análisis realizado por él mismo entre 1976-1977 sobre el contenido de los rotativos barceloneses. La información recogida sobre una zona, tipo Sabadell y su comarca, demuestra que dicha barceloneses. La información recogida sobre una zona, tipo Sabadell y su comarca, demuestra que dicha
información es insuficiente, distorsionada y manipulada. El total de asuntos sabadellenses tratados en un año por la Prensa de Barcelona fue de 87. Diez de ellos ocuparon el 58 por ciento del espacio, y los otros 77 un 42 por ciento. El tratamiento global fue negativo en un 60 por ciento de los casos. 
difusión) y que no cuajaron ni debilitaron la consolidación de la prensa comarcal, que constituye un factor de prestigio cultural y colectivo que refuerza el puro servicio informativo ${ }^{28}$.

A favor o no de la zonificación informativa, de lo que no hay duda es de la importancia adquirida por la información local en los Medios de Comunicación Social. De hecho, el pulso mass-mediático gira actualmente en torno suyo, llegándose a cumplir los pronósticos que vaticinaron su empuje: «El futuro de la estructura informativa de España se va a consolidar sobre la base del fuerte desarrollo de la prensa de regiones $»^{29}$.

28 MACIÁ MERCADÉ, Juan: «Del siglo XVIII al XXI, cada vez con más potencialidad», en Anuncios, 26 enero1 febrero, 1987 , p. 4.

29 MACIÁ MERCADÉ, Juan: La comunicología regional..., op. cit., p. 5. 